\title{
Incidental Adrenal Nodules and Masses: The Imaging Approach
}

\author{
J. Willatt, ${ }^{1,2}$ S. Chong, ${ }^{1,2}$ J. A. Ruma, ${ }^{1,2}$ and J. Kuriakose ${ }^{1,2}$ \\ ${ }^{1}$ University of Michigan Health System, Ann Arbor, MI 48109, USA \\ ${ }^{2}$ Veterans Administration Hospital, Ann Arbor, MI 48105, USA
}

Correspondence should be addressed to J. Willatt; jwillatt@med.umich.edu

Received 24 February 2015; Accepted 12 April 2015

Academic Editor: Sabrina Corbetta

Copyright (C) 2015 J. Willatt et al. This is an open access article distributed under the Creative Commons Attribution License, which permits unrestricted use, distribution, and reproduction in any medium, provided the original work is properly cited.

Adrenal nodules are detected with increasing frequency. The National Institute of Health (NIH), American College of Radiology (ACR), and the American Association of Clinical Endocrinologists and American Association of Endocrine Surgeons (AACE/AAES) have produced guidelines for the management of incidental adrenal nodules. This review provides a summary of the consensus radiologic approach to these nodules.

\section{Introduction}

The burgeoning use of cross-sectional imaging in daily medical practice has led to a proportional increase in the burden of incidentally discovered nodules in the adrenal glands [1]. Adrenal nodules are seen in approximately $5 \%$ of abdominal CT scans $[1,2]$. Endocrinologists and radiologists have developed strategies for managing these "incidentalomas" [35].

Three questions need to be answered when defining a diagnostic pathway for incidentally discovered adrenal nodules [5].

(1) Is the lesion malignant, and if so, is it a primary adrenocortical cancer (ACC), or is it a metastasis?

(2) Is the lesion a pheochromocytoma?

(3) If the lesion is an adrenal adenoma, is it functioning?

The National Institute of Health (NIH) [6], the American College of Radiology (ACR) [7], and the American Association of Clinical Endocrinologists and American Association of Endocrine Surgeons (AACE/AAES) [8] have each produced guidelines from which a broad consensus can be reached. This paper focuses on the radiological component of the diagnostic work-up.

\section{Is the "Incidentaloma" an Adrenocortical Carcinoma or Metastatic Disease?}

In patients with a known malignancy, the likelihood of an adrenal nodule being malignant is approximately $25-36 \%$. However, in the population without a known malignancy, the prevalence is less than $0.5 \%$ [9-12]. Therefore a strategy for characterizing these nodules at minimum cost and without invasive tissue sampling is important. Techniques have been developed primarily using Computed Tomography (CT) and Magnetic Resonance Imaging (MRI) which spare the patient the need to undergo further testing for possible malignancy.

However, the assessment of size remains the single most useful determinant of the nature of silent adrenal lesions $[9,13]$ as survival rates following adrenalectomy are greater for smaller masses than for larger ones [14]. Although the specificity is low (42\%), a $4 \mathrm{~cm}$ cutoff as an indication for surgery is sensitive (93\%) [14], and this is therefore used as a threshold criterion alongside other factors such as imaging features, hormonal data, patient age, and the presence of abdominal pain.

\section{Diagnostic Approach}

The etiology of adrenal nodules can be determined on both $\mathrm{CT}$ and MRI for several entities without further work-up. 
(1) An adrenal myelolipoma is a benign tumor containing mature adipose tissue and hematopoietic tissue. They are usually asymptomatic. On rare occasions, they can become symptomatic as they can grow large. They can also spontaneously bleed. They can be diagnosed with very high specificity by CT and MRI as these are the most common adrenal lesions to contain large amounts of macroscopic fat. On MRI the fat components of most myelolipomas will demonstrate fat suppression [15]. On CT, if there are regions measuring less than -20 Hounsfield units (HU) signifying fat then the diagnosis can be made [16].

(2) Adrenal hemorrhage frequently occurs without symptoms. A history of trauma or anticoagulation is helpful. On CT they can appear as round or oval masses, often with adjacent inflammatory change. They decrease in size over time, but a residual organized hematoma can persist which may contain calcifications [17]. They demonstrate HU of 50-90 on noncontrast CT. On MRI they can be of variable signal intensities on T1-w and T2-w imaging, depending on the chronicity. They do not enhance following intravenous gadolinium chelate or iodinated contrast administration. CT and MRI (particularly with subtraction imaging) use enhancement characteristics to distinguish a simple adrenal hemorrhage from an adrenal mass [18].

(3) Adrenal cysts are not common. They show similar characteristics to renal or liver cysts. HU can be between -10 and 20, and they are hypointense on T1$\mathrm{w}$ imaging and hyperintense on $\mathrm{T} 2-\mathrm{w}$ imaging. They do not enhance after contrast administration.

(4) Adrenal adenomas represent $75 \%$ of the adrenal incidentalomas found on CT. Adenomas are benign tumors containing a variable amount of intracytoplasmic lipid. This enables the use of HU measurements on CT, or the chemical shift artifact on MRI, to characterize adenomas without the need for intravenous contrast [19-21]. If the lesion demonstrates HU of less than 10 on unenhanced CT then it can be declared a lipid rich adenoma with $98 \%$ specificity [22].

MRI can also be used to diagnose lipid rich adrenal adenomas using the dual gradient echo sequence. If an adrenal nodule loses signal on opposed imaging in comparison with in-phase imaging then it can be declared an adenoma [23]. More often than not this is seen with the naked eye. However, for more equivocal cases a threshold of $16.5 \%$ signal loss can be used [24]. This is known as the signal intensity index. Chemical shift MRI (CS-MRI) is more sensitive than unenhanced CT for intracytoplasmic lipid content and can diagnose many of the nodules which demonstrate HU of between 10 and 30 as lipid rich adenomas [25].

$25 \%$ of adrenal adenomas contain insufficient intracytoplasmic lipid to conform to the noncontrast features described for lipid rich adenomas. These require further characterization with contrast-enhanced CT [26-29].
The "adrenal protocol" CT begins with an unenhanced set of images. If the lesion does not demonstrate HU of 10 or less then intravenous iodinated contrast is given. The technique is based on the enhancement characteristics of adenomas which lose contrast more rapidly than metastases. A contrast "washout" calculation is therefore performed which uses the HU of the nodule before contrast injection, 60-70 seconds after contrast, and at a "delayed" phase of 15 minutes. The "absolute percentage of washout" (APW) is calculated using the following formula:

$$
\begin{gathered}
\text { APW }=[(\text { enhanced HU }-15 \text {-minute delayed HU }) \\
\div(\text { enhanced HU }- \text { unenhanced } \mathrm{HU})] \times 100 .
\end{gathered}
$$

If the absolute washout is greater than $60 \%$ then this classifies the lesion as a benign adenoma [28].

If a nodule is noted on a single phase contrast-enhanced $\mathrm{CT}$, then a relative percentage washout (RPW) can be calculated if a 15-minute delayed phase is subsequently performed:

$$
\begin{aligned}
& \mathrm{RPW}=[(\text { enhanced } \mathrm{HU}-15 \text {-minute delayed } \mathrm{HU}) \\
& \quad \div(\text { enhanced } \mathrm{HU})] \times 100
\end{aligned}
$$

If the relative washout is greater than $50 \%$ then this classifies the lesion as a benign adenoma [29].

These formulae have been validated demonstrating accuracy of more than $96 \%$ [30].

Caution should be applied when patients have histories of renal cell carcinoma or hepatocellular carcinoma, as metastases from these primary tumors can, on rare occasions, be mistaken for adrenal adenomas on CS-MRI or on adrenal washout CT [31-33]. Interval growth differentiates these malignant entities from adenomas. Other lesions that have been reported to demonstrate intracytoplasmic or even gross lipid are pheochromocytomas, adrenal lymphangiomas, and adrenocortical carcinomas [34-39]. Again lesion growth, size, and the presence of calcification combined with clinical suspicion and laboratory values are helpful in distinguishing these tumors from adenomas.

\section{Pheochromocytoma and Malignancy}

If a nodule cannot be diagnosed to be one of the benign entities above, a history of current or previous malignancy should be sought. Pheochromocytoma, primary adrenocortical carcinoma, and metastasis should now be excluded.

$10 \%$ of pheochromocytomas are bilateral and $10 \%$ are malignant. On CT, they can be of homogeneous or heterogenous density [40, 41]. On MRI they are often, but not always, of high signal intensity on T2-w imaging [40] and enhance rapidly. As they have been shown to demonstrate similar washout characteristics to adenomas [42] further evaluation with urine or plasma metanephrine levels is necessary, and positron emission tomography (PET) can be useful with either FDG (18-fluoro-2-deoxy-D-glucose) or MTO (11Cmetomidate) [43].

Adrenocortical carcinoma is rare, with a prevalence of 12 in 1 million, and has a poor prognosis [44]. Metastases are 
more common than ACC [45]. When a large adrenal mass is found incidentally then a search for a primary tumor or for further metastatic disease can be performed, potentially including the use of PET/CT [46].

ACC comprises less than $2 \%$ of adrenal incidentalomas measuring less than $4 \mathrm{~cm}$ and $25 \%$ of lesions measuring greater than $6 \mathrm{~cm} \mathrm{[6].} \mathrm{A} \mathrm{cutoff} \mathrm{of} 4 \mathrm{~cm}$ can be used to decide if an adrenal mass is benign or malignant with greater than $90 \%$ sensitivity $[13,47,48]$. Other findings suggestive of malignancy are an irregular border, central areas of necrosis, and invasion of adjacent structures including the IVC and the liver [49]. However, metastatic disease is rare in patients without a known history of malignancy $[11,50]$. Lymphoma, melanoma, lung, breast, renal, and gastric tumors are the most common origins, and, in patients with these diagnoses, an adrenal mass is likely to be metastatic [51].

In 2010 the ACR published a white paper which included a flow chart on incidental adrenal nodule findings [52]. The flow chart (Figure 1) can be summarized as follows.

(1) If a nodule of any size can be diagnosed as a myelolipoma or a lipid rich adenoma then no further imaging is warranted.

(2) A nodule measuring $4 \mathrm{~cm}$ or less which demonstrates benign imaging features such as low density, homogeneity, and smooth margins can be followed with a single further CT or MRI if there is no prior imaging with which to compare the size. If it is stable in size after one year it can be regarded as benign and does not need any further follow-up.

(3) If a 1-4 cm nodule demonstrates suspicious imaging features such as heterogeneity, necrosis, or irregular margins, or if it can be shown to be growing either retrospectively or at follow-up, then an adrenal nodule work-up should commence. This would include noncontrast CT or MRI, if not performed already. If the nodule is not diagnosed on these studies as a lipid rich adenoma, then an adrenal washout CT can be performed to see if it is a lipid poor adenoma. If it enhances and is therefore not a cyst but does not meet the washout criteria for an adenoma, then the level of suspicion should be raised and biopsy considered.

(4) If an adrenal mass measures more than $4 \mathrm{~cm}$ then a history of malignancy should be sought. If there is no history, then resection should be considered given the incidence of ACC in this group. Care should be taken to biochemically exclude a pheochromocytoma before intervention. If there is a history of malignancy, then PET/CT can be used to establish the location(s) of further disease, and, in the absence of a tissue diagnosis, biopsy can be considered.

\section{Adrenal Biopsy}

Biopsy of the adrenal glands can be technically challenging because of their locations, between the right kidney and liver or the left kidney and spleen or stomach. An axial approach will often transgress the diaphragm. The lower ribs extend below the level of the adrenal glands making visualization with ultrasound difficult. There is very little literature on adrenal biopsy in comparison with that of the liver or kidneys. Fine needle aspiration (FNA) has often been preferred over core biopsy because of the risks involved.

Adrenal biopsy is only performed, therefore, when the diagnostic imaging pathways have failed to lead to a diagnosis, and even then masses over $4 \mathrm{~cm}$ in size are often resected without prior tissue diagnosis. Pneumothorax, severe hemorrhage, and hypertensive crisis have been reported following adrenal nodule FNA $[53,54]$. Biopsy is generally reserved for patients with a history of cancer to determine if the mass is metastatic from the known primary tumor.

\section{Pitfalls}

Collision tumors, where adjacent but histologically distinct entities are found within the same adrenal nodule, are rare, but recognized $[55,56]$. These often consist of a contiguous adrenal adenoma and a metastasis from a remote primary malignancy [55], but other combinations including adenoma with myelolipoma, hemangioma with adenoma, and adrenocortical carcinoma with myelolipoma are seen. Vigilance is required on the part of radiologists to ensure that all components of a nodule are assessed.

Before biopsy, ablation, or surgery, pheochromocytoma should be ruled out biochemically [6]. Even after ruling out pheochromocytoma, hypertensive crises are common when adrenal procedures are performed. Monitoring with an arterial line and close availability of antihypertensives are required.

\section{Biochemical Evaluation}

Patients who have an adrenal incidentaloma need to undergo a clinical examination to exclude a functioning tumor $[6,8]$. If the lesion is not a myelolipoma then biochemical evaluations for autonomous cortisol production, for pheochromocytoma, and, in patients who are hypertensive, for primary hyperaldosteronism should be performed at detection [4] and annually for 5 years.

\section{Imaging Follow-Up}

Approximately 15\% of adrenal incidentalomas increase in size during follow-up. Known malignant masses can remain unchanged in size over extended periods. In one study $12 \%$ of malignancies did not increase in size over 36 months [57]. Follow-up of adrenal nodules with CT is therefore controversial $[4,50]$. However, the AACE/AAES guidelines suggest that for a nodule measuring more than $1 \mathrm{~cm}$ and less than $4 \mathrm{~cm}$, repeat imaging with noncontrast CT should be performed at 3-6 months and annually for one to two years [8]. If the mass grows or becomes hormonally active then adrenalectomy should be performed.

Patients with masses measuring more than $4 \mathrm{~cm}$ should undergo evaluation for adrenalectomy. 


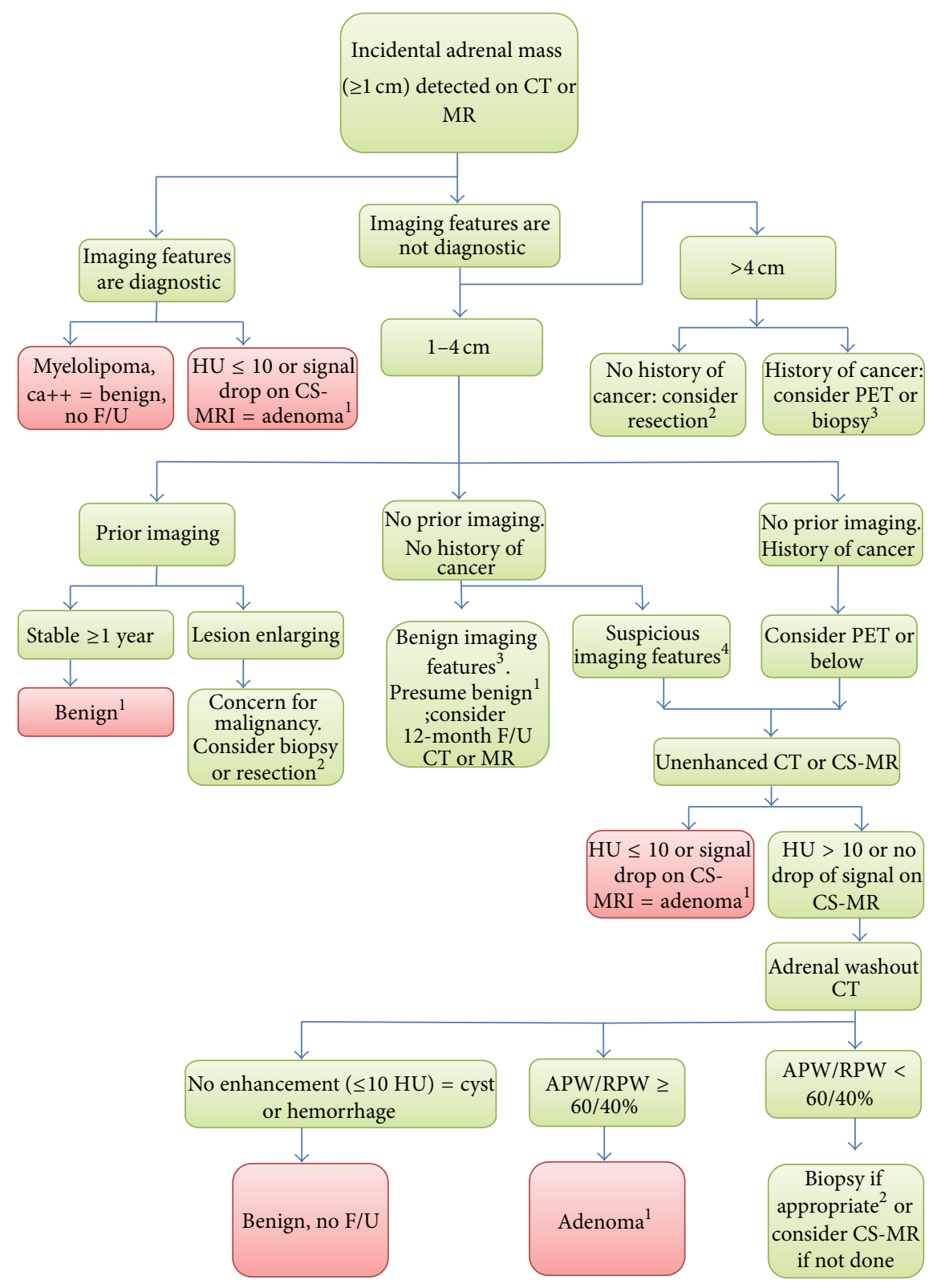

1: if patient has clinical signs or symptoms of adrenal hyperfunction, consider biochemical evaluation, 2: consider biochemical testing to exclude pheochromocytoma,

3: benign imaging features = homogeneous, low density, and smooth margins,

4: suspicious imaging features $=$ heterogeneous, necrosis, and irregular margins, APW: absolute percentage of washout,

RPW: relative percentage of washout,

CS-MR: chemical shift MRI,

F/U: follow-up,

HU: hounsfield unit.

FIGURE 1: ACR guidelines flow chart [52].

\section{Conclusion}

Incidentally discovered adrenal nodules measuring $10 \mathrm{~mm}$ or less in patients without a history of cancer are followed up clinically, but not radiologically, unless a biochemical abnormality is discovered. Nodules measuring between $10 \mathrm{~mm}$ and $4 \mathrm{~cm}$ should undergo radiological evaluation until they are diagnosed. If they cannot be diagnosed then they can be 
followed with imaging for up to two years. Masses measuring greater than $4 \mathrm{~cm}$, unless they are determined to be benign and they are asymptomatic, are removed surgically. Biochemical evaluation for pheochromocytoma should be carried out before biopsy or surgery is performed.

\section{Conflict of Interests}

The authors declare that there is no conflict of interests regarding the publication of this paper.

\section{References}

[1] S. Bovio, A. Cataldi, G. Reimondo et al., "Prevalence of adrenal incidentaloma in a contemporary computerized tomography series," Journal of Endocrinological Investigation, vol. 29, no. 4, pp. 298-302, 2006.

[2] E. M. Minnaar, K. E. Human, D. Henneman, C. Y. Nio, P. H. Bisschop, and E. J. M. Nieveen van Dijkum, "An adrenal incidentaloma: how often is it detected and what are the consequences?” ISRN Radiology, vol. 2013, Article ID 871959, 4 pages, 2013.

[3] P. Anagnostis, A. Karagiannis, K. Tziomalos, A. I. Kakafika, V. G. Athyros, and D. P. Mikhailidis, "Adrenal incidentaloma: a diagnostic challenge," Hormones, vol. 8, no. 3, pp. 163-184, 2009.

[4] D. Aron, M. Terzolo, and T. J. Cawood, "Adrenal incidentalomas," Best Practice and Research: Clinical Endocrinology and Metabolism, vol. 26, no. 1, pp. 69-82, 2012.

[5] M. Terzolo, S. Bovio, A. Pia, G. Reimondo, and A. Angeli, "Management of adrenal incidentaloma," Best Practice \& Research Clinical Endocrinology \& Metabolism, vol. 23, no. 2, pp. 233-243, 2009.

[6] "NIH state-of-the-science statement on management of the clinically inapparent adrenal mass ('incidentaloma')," NIH Consensus and State-of-the-Science Statements, vol. 19, no. 2, pp. 125, 2002.

[7] P. L. Choyke and ACR Committee on Appropriateness Criteria, "ACR appropriateness criteria on incidentally discovered adrenal mass," Journal of the American College of Radiology, vol. 3, no. 7, pp. 498-504, 2006.

[8] M. A. Zeiger, G. B. Thompson, Q.-Y. Duh et al., "American Association of Clinical Endocrinologists and American Association of Endocrine Surgeons Medical Guidelines for the management of adrenal incidentalomas: executive summary of recommendations," Endocrine Practice, vol. 15, no. 5, pp. 450453, 2009.

[9] J. H. Song, F. S. Chaudhry, and W. W. Mayo-Smith, "The incidental adrenal mass on CT: prevalence of adrenal disease in 1,049 consecutive adrenal masses in patients with no known malignancy," The American Journal of Roentgenology, vol. 190, no. 5, pp. 1163-1168, 2008.

[10] M. F. Herrera, C. S. Grant, J. A. van Heerden, P. F. Sheedy II, and D. M. Iistrup, "Incidentally discovered adrenal tumors: an institutional perspective," Surgery, vol. 110, no. 6, pp. 1014-1021, 1991.

[11] J. E. Lee, D. B. Evans, R. C. Hickey et al., "Unknown primary cancer presenting as an adrenal mass: frequency and implications for diagnostic evaluation of adrenal incidentalomas," Surgery, vol. 124, no. 6, pp. 1115-1122, 1998.

[12] H. Gajraj and A. E. Young, "Adrenal incidentaloma," British Journal of Surgery, vol. 80, no. 4, pp. 422-426, 1993.
[13] A. Angeli, G. Osella, A. Alì, and M. Terzolo, "Adrenal incidentaloma: an overview of clinical and epidemiological data from the National Italian Study Group," Hormone Research, vol. 47, no. 4-6, pp. 279-283, 1997.

[14] F. Mantero, M. Terzolo, G. Arnaldi et al., "A survey on adrenal incidentaloma in Italy. Study group on adrenal tumors of the Italian society of endocrinology," The Journal of Clinical Endocrinology \& Metabolism, vol. 85, no. 2, pp. 637-644, 2000.

[15] P. Boraschi, G. Braccini, L. Grassi et al., "Incidentally discovered adrenal masses: evaluation with Gadolinium enhancement and fat-suppressed MR imaging at 0.5 T,' European Journal of Radiology, vol. 24, no. 3, pp. 245-252, 1997.

[16] P. J. Kenney, B. J. Wagner, P. Rao, and C. S. Heffess, "Myelolipoma: CT and pathologic features," Radiology, vol. 208, no. 1, pp. 87-95, 1998.

[17] K. J. Too and V. A. Duddalwar, "Imaging of traumatic adrenal injury," Emergency Radiology, vol. 19, no. 6, pp. 499-503, 2012.

[18] E. Jordan, L. Poder, J. Courtier, V. Sai, A. Jung, and F. V. Coakley, "Imaging of nontraumatic adrenal hemorrhage," The American Journal of Roentgenology, vol. 199, no. 1, pp. W91-W98, 2012.

[19] M. Korobkin, T. J. Giordano, F. J. Brodeur et al., "Adrenal adenomas: relationship between histologic lipid and CT and MR findings," Radiology, vol. 200, no. 3, pp. 743-747, 1996.

[20] G. M. Israel, M. Korobkin, C. Wang, E. N. Hecht, and G. A. Krinsky, "Comparison of unenhanced CT and chemical shift MRI in evaluating lipid-rich adrenal adenomas," The American Journal of Roentgenology, vol. 183, no. 1, pp. 215-219, 2004.

[21] M. Korobkin, F. J. Brodeur, G. G. Yutzy et al., "Differentiation of adrenal adenomas from nonadenomas using CT attenuation values," The American Journal of Roentgenology, vol. 166, no. 3, pp. 531-536, 1996.

[22] G. W. L. Boland, M. J. Lee, G. S. Gazelle, E. F. Halpern, M. M. J. McNicholas, and P. R. Mueller, "Characterization of adrenal masses using unenhanced CT: an analysis of the CT literature," American Journal of Roentgenology, vol. 171, no. 1, pp. 201-204, 1998.

[23] F. Fujiyoshi, M. Nakajo, Y. Fukukura, and S. Tsuchimochi, "Characterization of adrenal tumors by chemical shift fast low-angle shot MR imaging: comparison of four methods of quantitative evaluation," American Journal of Roentgenology, vol. 180, no. 6, pp. 1649-1657, 2003.

[24] G. W. L. Boland, M. A. Blake, P. F. Hahn, and W. W. MayoSmith, "Incidental adrenal lesions: principles, techniques, and algorithms for imaging characterization," Radiology, vol. 249, no. 3, pp. 756-775, 2008.

[25] M. A. Haider, S. Ghai, K. Jhaveri, and G. Lockwood, "Chemical shift MR imaging of hyperattenuating $(<10 \mathrm{HU})$ adrenal masses: Does it still have a role?” Radiology, vol. 231, no. 3, pp. 711-716, 2004.

[26] M. Korobkin, F. J. Brodeur, I. R. Francis, L. E. Quint, N. R. Dunnick, and F. Londy, "CT time-attenuation washout curves of adrenal adenomas and nonadenomas," American Journal of Roentgenology, vol. 170, no. 3, pp. 747-752, 1998.

[27] D. H. Szolar and F. H. Kammerhuber, "Adrenal adenomas and nonadenomas: assessment of washout at delayed contrastenhanced CT," Radiology, vol. 207, no. 2, pp. 369-375, 1998.

[28] E. M. Caoili, M. Korobkin, I. R. Francis, R. H. Cohan, and N. R. Dunnick, "Delayed enhanced CT of lipid-poor adrenal adenomas," The American Journal of Roentgenology, vol. 175, no. 5, pp. 1411-1415, 2000. 
[29] C. S. Pena, G. W. L. Boland, P. F. Hahn, M. J. Lee, and P. R. Mueller, "Characterization of indeterminate (lipid-poor) adrenal masses: use of washout characteristics at contrastenhanced CT," Radiology, vol. 217, no. 3, pp. 798-802, 2000.

[30] E. M. Caoili, M. Korobkin, I. R. Francis et al., "Adrenal masses: characterization with combined unenhanced delayed enhanced CT," Radiology, vol. 222, no. 3, pp. 629-633, 2002.

[31] Y. A. Choi, C. K. Kim, B. K. Park, and B. Kim, "Evaluation of adrenal metastases from renal cell carcinoma and hepatocellular carcinoma: use of delayed contrast-enhanced CT," Radiology, vol. 266, no. 2, pp. 514-520, 2013.

[32] K. Shinozaki, K. Yoshimitsu, H. Honda et al., "Metastatic adrenal tumor from clear-cell renal cell carcinoma: a pitfall of chemical shift MR imaging," Abdominal Imaging, vol. 26, no. 4, pp. 439-442, 2001.

[33] B. D. Sydow, M. A. Rosen, and E. S. Siegelman, "Intracellular lipid within metastatic hepatocellular carcinoma of the adrenal gland: a potential diagnostic pitfall of chemical shift imaging of the adrenal gland," American Journal of Roentgenology, vol. 187, no. 5, pp. W550-W551, 2006.

[34] N. Bharwani, A. G. Rockall, A. Sahdev et al., "Adrenocortical carcinoma: the range of appearances on CT and MRI," The American Journal of Roentgenology, vol. 196, no. 6, pp. W706W714, 2011.

[35] M. A. Blake, S. K. Krishnamoorthy, G. W. Boland et al., "Lowdensity pheochromocytoma on CT: a mimicker of adrenal adenoma," American Journal of Roentgenology, vol. 181, no. 6, pp. 1663-1668, 2003.

[36] N. Egbert, K. M. Elsayes, S. Azar, and E. M. Caoili, “Computed tomography of adrenocortical carcinoma containing macroscopic fat," Cancer Imaging, vol. 10, pp. 198-200, 2010.

[37] K. M. Elsayes, G. Mukundan, V. R. Narra et al., "Adrenal masses: MR imaging features with pathologic correlation," Radiographics, vol. 24, supplement 1, pp. S73-S86, 2004.

[38] N. Schieda, O. Al Dandan, A. Kielar, T. Flood, M. McInnes, and E. Siegelman, "Pitfalls of adrenal imaging with chemical shift MRI,” Clinical Radiology, vol. 69, no. 11, pp. 1186-1197, 2014.

[39] H. M. Zhang, N. D. Perrier, E. G. Grubbs et al., "CT features and quantification of the characteristics of adrenocortical carcinomas on unenhanced and contrast-enhanced studies," Clinical Radiology, vol. 67, no. 1, pp. 38-46, 2012.

[40] M. A. Blake, M. K. Kalra, M. M. Maher et al., "Pheochromocytoma: an imaging chameleon," Radiographics, vol. 24, supplement 1, pp. S87-S99, 2004.

[41] G. A. Motta-Ramirez, E. M. Remer, B. R. Herts, I. S. Gill, and A. H. Hamrahian, "Comparison of CT findings in symptomatic and incidentally discovered pheochromocytomas," The American Journal of Roentgenology, vol. 185, no. 3, pp. 684-688, 2005.

[42] J. Patel, M. S. Davenport, R. H. Cohan, and E. M. Caoili, "Can established CT attenuation and washout criteria for adrenal adenoma accurately exclude pheochromocytoma?" The American Journal of Roentgenology, vol. 201, no. 1, pp. 122-127, 2013.

[43] W. F. Young Jr., "The incidentally discovered adrenal mass," The New England Journal of Medicine, vol. 356, no. 6, pp. 601-610, 2007.

[44] B. Allolio and M. Fassnacht, "Clinical review: adrenocortical carcinoma: clinical update," The Journal of Clinical Endocrinology and Metabolism, vol. 91, no. 6, pp. 2027-2037, 2006.

[45] J. T. Lenert, C. C. Barnett Jr., A. P. Kudelka et al., "Evaluation and surgical resection of adrenal masses in patients with a history of extra-adrenal malignancy," Surgery, vol. 130, no. 6, pp. 10601067, 2001.

[46] M. D. Gross, P. G. Gauger, M. Djekidel, and D. Rubello, "The role of PET in the surgical approach to adrenal disease," European Journal of Surgical Oncology, vol. 35, no. 11, pp. 1137-1145, 2009.

[47] Y. K. Hee, G. K. Sin, W. L. Kye et al., "Clinical study of adrenal incidentaloma in Korea," Korean Journal of Internal Medicine, vol. 20, no. 4, pp. 303-309, 2005.

[48] J. Kim, K. H. Bae, Y. K. Choi et al., "Clinical characteristics for 348 patients with adrenal incidentaloma," Endocrinology and Metabolism, vol. 28, no. 1, pp. 20-25, 2013.

[49] J. H. Song, D. J. Grand, M. D. Beland, K. J. Chang, J. T. Machan, and W. W. Mayo-Smith, "Morphologic features of 211 adrenal masses at initial contrast-enhanced CT: can we differentiate benign from malignant lesions using imaging features alone?" The American Journal of Roentgenology, vol. 201, no. 6, pp. 12481253, 2013.

[50] W. F. Young Jr., "Management approaches to adrenal incidentalomas: a view from Rochester, Minnesota," Endocrinology and Metabolism Clinics of North America, vol. 29, no. 1, pp. 159-185, 2000.

[51] K.-Y. Lam and C.-Y. Lo, "Metastatic tumours of the adrenal glands: a 30-year experience in a teaching hospital," Clinical Endocrinology, vol. 56, no. 1, pp. 95-101, 2002.

[52] L. L. Berland, S. G. Silverman, R. M. Gore et al., "Managing incidental findings on abdominal CT: white paper of the ACR incidental findings committee," Journal of the American College of Radiology, vol. 7, no. 10, pp. 754-773, 2010.

[53] G. Casola, V. Nicolet, E. VanSonnenberg et al., "Unsuspected pheochromocytoma: risk of blood-pressure alterations during percutaneous adrenal biopsy," Radiology, vol. 159, no. 3, pp. 733735, 1986.

[54] S. J. McCorkell and N. L. Niles, "Fine-needle aspiration of catecholamine-producing adrenal masses: a possibly fatal mistake," American Journal of Roentgenology, vol. 145, no. 1, pp. 113114, 1985.

[55] V. S. Katabathina, E. Flaherty, R. Kaza, V. Ojili, K. N. Chintapalli, and S. R. Prasad, "Adrenal collision tumors and their mimics: multimodality imaging findings," Cancer Imaging, vol. 13, no. 4, pp. 602-610, 2013.

[56] L. H. Schwarte, M. Macari, A. G. Huvos, and D. M. Panicek, "Collision tumors of the adrenal gland: demonstration and characterization at MR imaging," Radiology, vol. 201, no. 3, pp. 757-760, 1996.

[57] S. Yener, S. Ertilav, M. Secil et al., "Prospective evaluation of tumor size and hormonal status in adrenal incidentalomas," Journal of Endocrinological Investigation, vol. 33, no. 1, pp. 3236, 2010. 


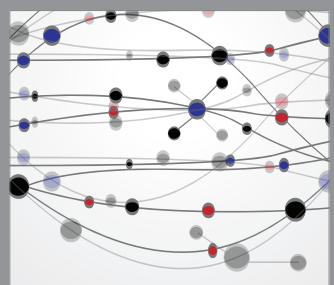

The Scientific World Journal
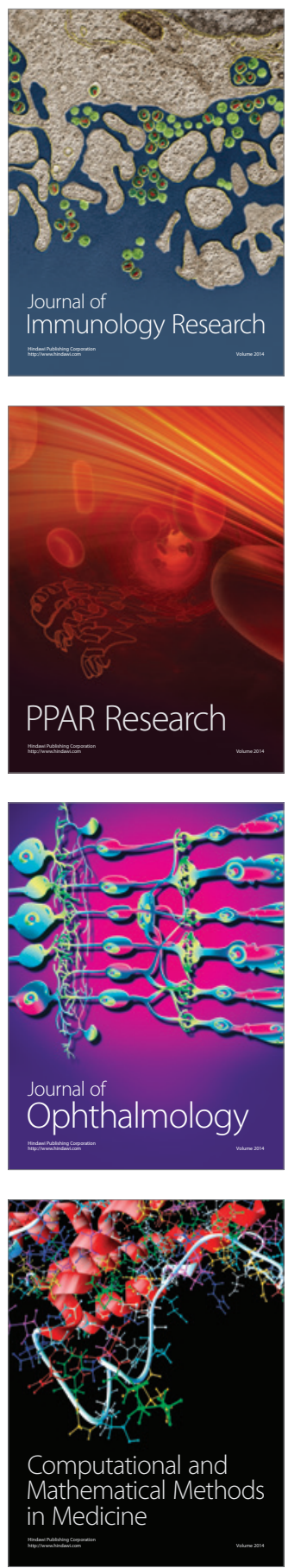

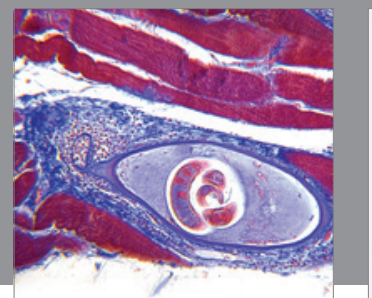

Gastroenterology

Research and Practice
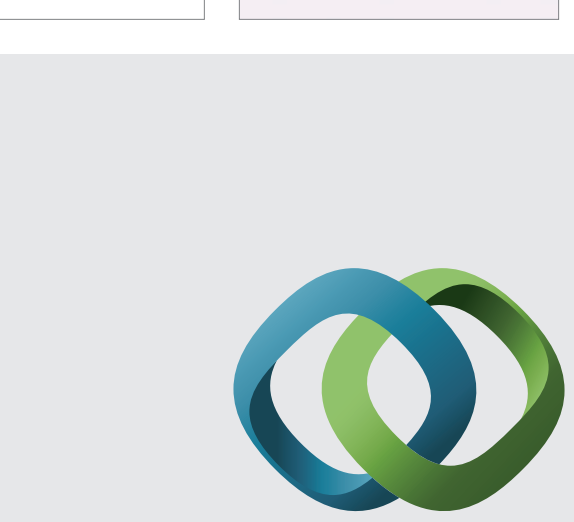

\section{Hindawi}

Submit your manuscripts at

http://www.hindawi.com
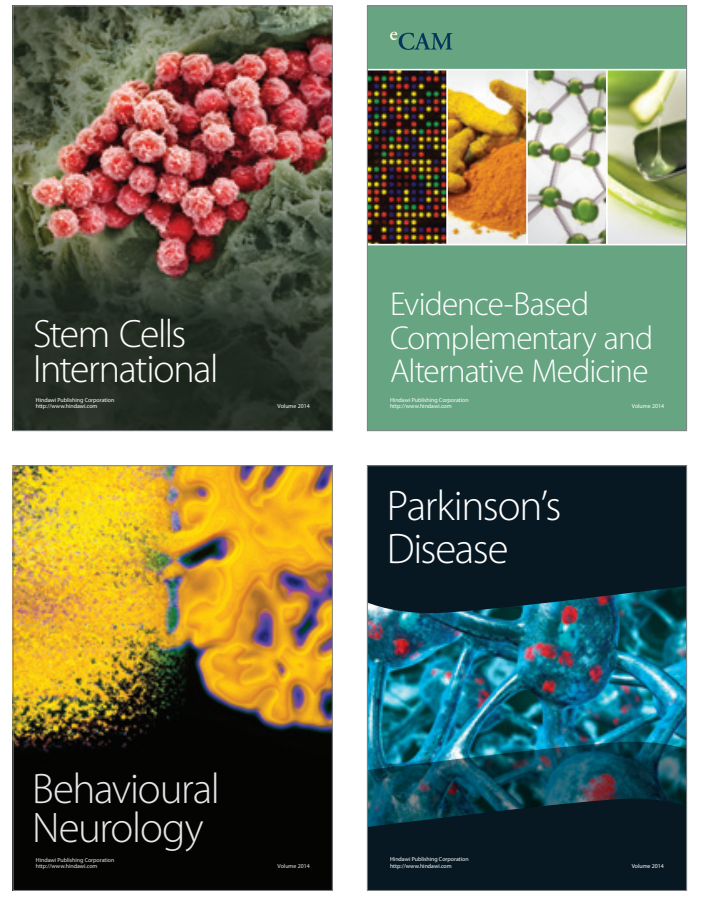
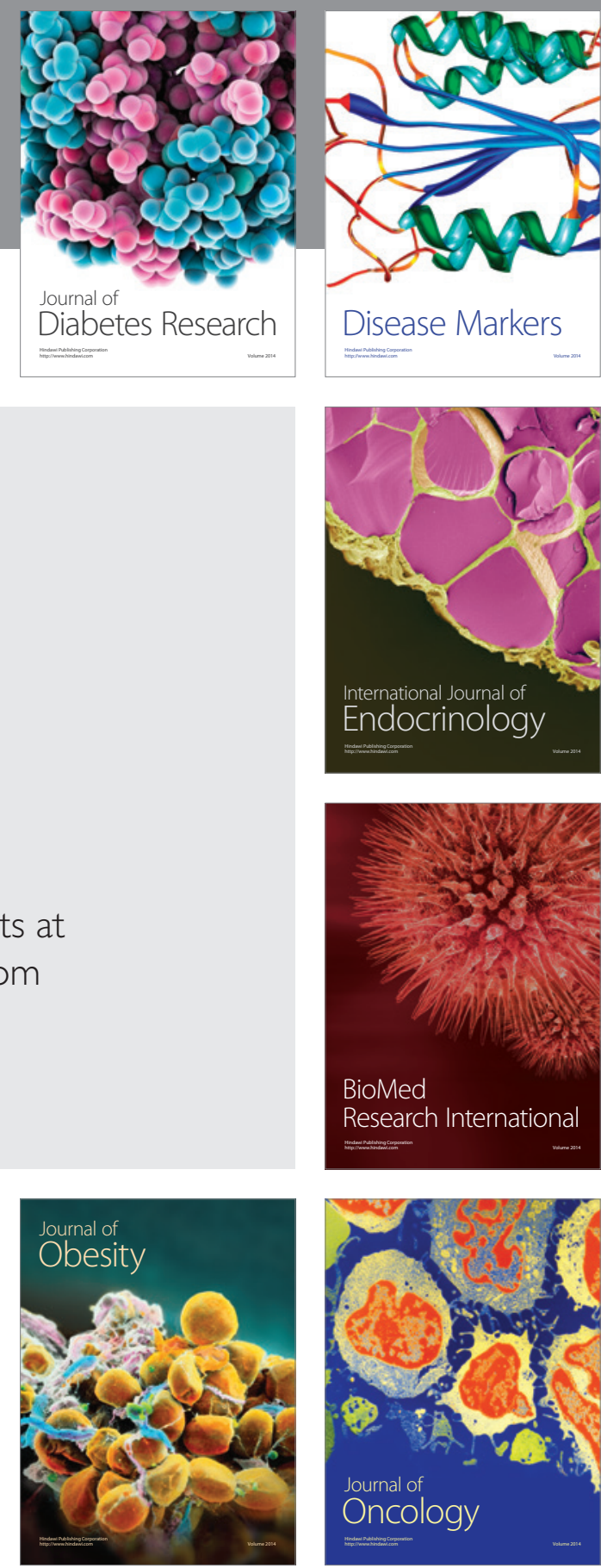

Disease Markers
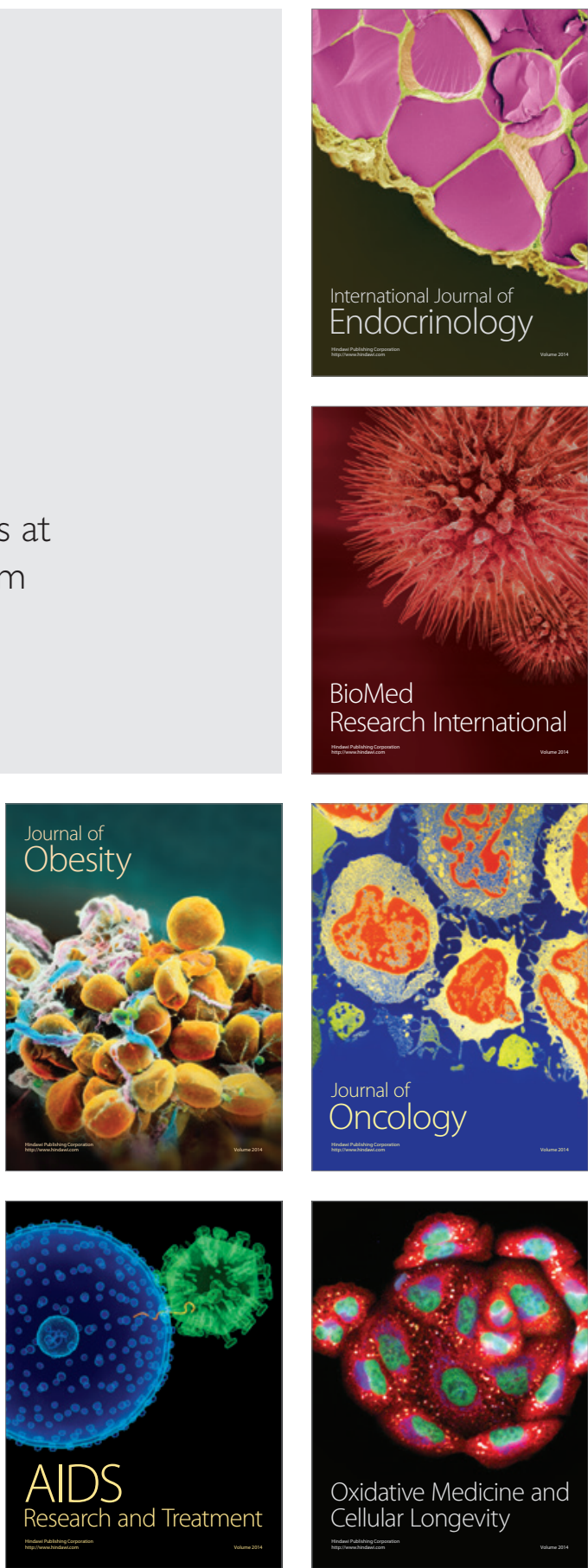